\title{
Coping with inflation and exchange rate shocks in the South African economy
}

W de Wet*

In conducting monetary policy, central banks typically make use of a wide variety of variables that play very different roles. At the one end of the spectrum stands the ultimate target of policy; while at the other end of the spectrum is the instrument or instruments by which policy is implemented. Because of long lags and very indirect connections between the instruments and the ultimate goal, most central banks make use of other variables that stand between the ultimate goal and the instrument. These can be classified as intermediate targets or operational targets. The operational target should be closely linked to the ultimate target of policy and be influenced by the instrument of policy (Balino and Cottarelli: 1994).

In recent years central banks have moved away from the use of monetary aggregates as intermediate targets (like the M3 money supply) because of their unpredictability and changes in the financial structure that weakened the link between monetary aggregates and the ultimate target (Freedman: 1994). In ignoring intermediate targets, operational targets became the direct link between the

\footnotetext{
Department of Economics, University of Pretoria, Pretoria. Revised version of the paper read at the Biennial Conference of the Economic Society of South Africa, 13 September 2001. The author would like to thank the anonymous referee for his valuable comments and suggestions on this paper.
} 
instrument and the ultimate goal. The operational target in most countries is a short-term interest rate. This operational target provides leading or contemporaneous information about potential movements in the ultimate target variable, but is usually not itself treated as an object to be controlled.

The Reserve Bank of South Africa has set its ultimate target in terms of the inflation rate and is currently using a short-term interest rate as its operational variable (Mboweni: 2000). In this paper a monetary tool - the Monetary Conditions Index (MC1) - is proposed that can be used as a rule or simply a guidepost of the stance of monetary conditions in South Africa indicating how the operational target should be adjusted in order to obtain a more stable macroeconomic environment.

\section{Monetary policy in South Africa}

The monetary policy environment in South Africa has moved to an increasingly open economy over the past ten years, characterised by a (relatively) low level of inflation and large and unpredictable movements in the prices of equities, bonds and foreign exchange, or financial assets in general. This volatility in part reflects the dependence of asset prices on expectations, but the large movements in these prices also raise the question of the appropriate response of monetary policy (Smets: 1997:1).

Within this context the Reserve Bank's response to unexpected changes in asset prices should depend on how these changes affect the inflation outlook. First, changes in asset prices might affect aggregate demand directly, through a change in household wealth and consumption. Secondly, sharp changes in exchange rates will affect aggregate demand through a change in imports and exports. If 
changes thus imply a rise in the inflation forecast, policy should be tightened and vice versa.

When policymakers seek to stabilise prices and output, optimal rules in open economies differ considerably from optimal rules in closed economies. In open economies, stability is best achieved by targeting long-run inflation, a measure of inflation adjusted to remove transitory effects of exchange rate movements (Ball: 2000:3). Under a flexible exchange rate system, monetary actions have their effect through both interest rates and exchange rates. Since most economic agents are net debtors, higher interest rates raise the financial costs of their operations, which eventually lead to a fall in their demand. Real exchange rate movements influence economic activity through their effect on international competitiveness of domestic products. With these transmission mechanisms in mind, central banks must choose an operational target to achieve their goal (Duguay: 1994: 38).

Using the interest rate as operational target, the potential danger exists that the monetary authorities might ignore or underestimate in essence the very important exchange rate transmission mechanism through which monetary policy operates. An information measure exists, that should be part of the information set of monetary authorities, the "Monetary Conditions Index", defined as an average of the interest rate and exchange rate.

\section{What is a Monetary Conditions Index?}

First of all, as mentioned above, the Monetary Conditions Index or MCI is an information tool used to determine the monetary situation in a country in order to achieve an ultimate goal. Technically, the Monetary Conditions Index is 
defined as a combination of changes in the short-term interest rate and the multilateral exchange rate from some arbitrary base period. In other words, it is a weighted index of the real interest rate and the real effective exchange rate, with the weights determined by the relative influence that the real interest rate and the real exchange rate have on inflation (Freedman: 1994).

Thus, one can interpret the MCI as the percentage point change in the real interest rate equivalent to the combined change in the real interest rate and the real exchange rate since the base period. Moreover, since the MCI is always measured relative to a given base period, comparing the MCI at two points in time gives a measure of the degree of tightening or easing between those two points of time. If a central bank wants to keep the monetary situation in a country stable, they have to keep the MCI constant.

Empirical evidence suggests that the exchange rate plays a significant role in countries like New Zealand and Canada. In New Zealand the interest rate seems to be twice as important as the exchange rate in determining aggregate demand and the MCI has therefore weights of 2 to 1 (Dennis: 1997). In Canada the MCI has weights of 3:1 (Duguay: 1994). The role that the MCI plays in both countries differs also in the degree of transparency, importance and flexibility. In the case of New Zealand, the MCI is seen as more of a summary measure and information variable of past and current monetary conditions, and also as a guide to the interforecast implementation of monetary policy. Although it has a significant role in policy setting, it only stays an information guide and by no means a rule (Hunt and Orr: 1999). The Bank of Canada uses the MCI as a policy rule that needs to be kept within certain bands in order to reach the ultimate goal of inflation stability. 
Given the difficulty and the ability to accurately forecast the exchange rate, the MCI becomes a useful indication for policy makers of how unexpected movements in the exchange rate have influenced monetary conditions in a country.

\section{The interest rate, MCI and shocks to the economy}

Once the policy of the central bank has been formulated, the authorities must decide on how to implement it. Two alternative implementation strategies are compared here. The first is the so-called 'interest rate' strategy, where the official interest rate is adjusted only after a formal assessment of the inflation outlook. This is consistent with the framework that operates in countries like South Africa, Australia and the United States. At the other end of the scale is the 'MCI' strategy where the policy instrument is adjusted to keep the MCI constant. In this case the MCI is used as a simple policy rule to adjust the official interest rate in response to unexpected changes in the exchange rate.

Using a model developed by Ball (2000: 13), it is possible to determine which strategy - the 'interest rate' strategy, or the 'MCF strategy - is the most favourable strategy for a country. Consider the following model:

$$
\begin{aligned}
& \mathrm{Y}=\mathrm{D}+\mathrm{X} \\
& \mathrm{X}=\mathrm{F}
\end{aligned}
$$

where $\mathrm{Y}$ is output, $\mathrm{D}$ is domestic spending, $\mathrm{X}$ is net exports and $\mathrm{F}$ is net foreign investment by domestic residents.

Equation (1) states that output is equal to the sum of domestic spending and net exports, while equation (2) states 
that net exports equals net foreign investment of residents.

The model further assumes that the variables in equation (1) and equation (2) are determined by

$$
\begin{aligned}
& \mathrm{D}=-\beta \mathrm{r}+\mathrm{u}_{1} \\
& \mathrm{x}=-\delta \mathrm{e}+\mathrm{u}_{2} \\
& \mathrm{~F}=-\varphi \mathrm{r}+\varrho \mathrm{e}+\mathrm{u}_{3}
\end{aligned}
$$

Domestic spending depends negatively on the real interest rate $(r)$ and on shocks such as domestic policy $\left(\mathrm{u}_{1}\right)$. Exports depend negatively on the real exchange rate (e) and shocks to net exports $\left(\mathrm{u}_{2}\right)$. Net foreign investment by domestic residents depends negatively on the real interest rate and positively on the exchange rate. Note that an increase in net foreign investment (F) is equal to an outflow of investments from the country, i.e. a capital flight, while a decrease means residents bring more capital into the country. Net foreign investment also depends on shocks that arise in financial markets $\left(\mathrm{u}_{3}\right)$. Equation (2) is an accounting identity and although net export equals net foreign investment, the underlying factors that influence exports and foreign investment differs. It is this difference that plays a crucial role in monetary conditions.

Finding the reduced form for the exchange rate (e) as dependent variable using equation (4) and equation (5) the following relation emerges:

$\mathrm{e}=(\varphi /(\delta+\varrho)) \mathrm{r}+(1 /(\delta+\varrho)) \mathrm{u}_{2}-(1 /(\delta+\varrho)) \mathrm{u}_{3}$

A rise in e represents an exchange rate appreciation while a decline represents depreciation.

From equation (6) three scenarios for exchange rate fluctuations can be analysed depending on the nature of the 
shock to the system. Three factors influence the exchange rate - the real interest rate (r), shocks to net exports $\left(\mathrm{u}_{2}\right)$ and shocks to net foreign investment $\mathrm{u}_{3}$ Using Ball's (2000) argument, it is possible to determine which strategy will lead to more stable output and inflation - a strategy of formal assessment of the inflation outlook or a strategy that uses a MCI as implementation rule. Using his methodology, the possible outcome of each strategy is determined by analysing the impact of each shock on the system.

A shock to domestic spending does not change the relationship between the interest rate and the exchange rate — the shock term u, does not enter equation (6) Therefore an interest rate target will produce similar results on output and inflation, with or without the aid of a MCI.

When there is a shock to net exports (equation (4)) an interest rate strategy will keep output more stable than a MCI strategy. Suppose that exports rise because of an economic boom in one of the country's major trading partners. This results in a positive $\mathrm{u}_{2}$. Output increases under both strategies, but the rise is greater under the MCI strategy. With an interest rate strategy, a positive $\mathbf{u}_{\text {n }}$ increases net exports. This leads to an appreciation of the real exchange rate, but the resulting decrease in net exports is offset by the direct positive effect. At the same time domestic spending remains unchanged, thus higher net export increases output.

Under a MCI strategy policymakers will lower $r$ to offset the appreciation of the exchange rate and to keep the monetary conditions constant. This means $r$ is lower than under an interest rate strategy, and this results in a lower $\mathrm{e}$ through equation (6). As a result both domestic spending and net exports are higher than with an interest rate strategy. This leads to higher output and higher inflation 
than under a pure interest rate strategy.

When the shock is to net foreign investment, output will be more stable under a MCI strategy than under an interest rate strategy. To see this assume that there is a decline in net foreign investment - i.e. more capital flows to the country. In this case, the shock $\mathrm{u}_{3}$ is negative. A MCI strategy fully adjusts to conditions in order to smooth output.

Again first consider an interest rate strategy. Under this policy, equation (6) implies that a negative $\mathrm{u}_{3}$ raises e: capital flow appreciates the domestic currency. This appreciation lowers net exports. Once again domestic spending does not change, because the interest rate is held fixed. Consequently, aggregate output declines because of the decline in net exports.

Under a MCI strategy, the interest rate is lowered when there is an increase in capital flow to the country, in order to prevent the MCI from rising above its target. The shock produces a lower interest rate, a higher exchange rate and a constant MCI. The relationship between the interest rate and the exchange rate stays constant and output through equation (1) stays constant.

\section{The South African situation}

From the above analyses it is evident that depending on the type of shock to the economy, the method by which a central bank adjusts the interest rate will have different outcomes on the economy. It must be said however, that with a small open economy like South Africa, it is inevitable that over time the economy will experience both shocks to net exports and shocks to foreign net investment. The question to be asked however is what kind of shocks influences the South African economy? I give five reasons why shocks to foreign 
investments will almost entirely dominate shocks in the economy.

First of all South Africa is a developing country. This means that problems in any other developing country will also influence capital flows to and from South Africa. We therefore not only have to cope with shocks created by ourselves, but also with shocks created by any other developing country. Secondly, we are an African country, and unfortunately it is a continent plagued with political instability. South Africa is the major financial centre in Africa, and is seen as a control centre for capital flows in and out of Africa. Negative actions by our neighbours reflect negatively on us. This raises the risk premium and makes foreign investment more volatile. Thirdly, most of the foreign investments in South Africa are speculative of nature and this undeniably increases financial market volatility. The fourth reason is that South Africa is currently abolishing foreign exchange controls. Every time controls are relaxed, a capital flight is experienced for a period of time. The fifth reason is that South Africa's major trading partners are developed countries where trade and output is much more stable than in developing countries. Furthermore, our trading partners are well diversified, so a shock to trade with one country is unlikely to affect aggregate trade much.

Given these five reasons, I therefore argue that shocks to the financial market and in particular foreign investment are the dominant disturbance in our economy. This in turn leads to the fact that the interest rate as operational target must be used in union with a MCI, otherwise it will lead to even greater output and price fluctuations. A MCI strategy is the preferred policy for South Africa. 


\section{Developing a MCI for South Africa}

Using the definition of a MCI, a formula for the index is

$$
\begin{aligned}
\text { MCI } & =\lambda[\text { Real interest rate }- \text { real interest rate at base } \\
& \text { period }] \\
& +\alpha[(\text { Real effective exchange rate index / real } \\
& \text { effective exchange rate index at base period }) \\
& -1](100)
\end{aligned}
$$

In order to determine the relative weights that the real interest rate and the real effective exchange rate must have in the MCI, a relatively simple version of the expectationsaugmented Phillips curve is fitted. This provides estimates of the influence of the exchange rate and the interest rate on inflation. This regression attempts to estimate the relative ratio of the interest rate to exchange rate influence on inflation (not in absolute values). Note that the period under examination commences only in 1992. The reason for this is that prior to 1992 the economy was not open enough for the exchange rate to play a significant role in monetary policy. The estimated equation is of the form

$$
\Delta \mathrm{p}_{\mathrm{r}}=\Delta \mathrm{s}_{\mathrm{t}}+\mathrm{E}\left(\mathrm{y}_{\mathrm{r}}-\mathrm{y}_{\mathrm{r}}^{*}\right)+\Delta \mathrm{r}_{\mathrm{r}}
$$

where

$\Delta p_{t}=$ the quarterly growth in CPI

$\Delta \mathrm{s}_{1}=$ the change in the real effective exchange rate

$E\left(y_{t}-y_{t}^{*}\right)=$ the ratio of actual to potential output ${ }^{1}$

$\Delta \mathrm{r}_{\mathrm{t}}=$ change in the real interest rate

The exchange rate used was the real effective exchange rate, while the interest rate used was the real short-term Treasury bill rate. The gross domestic product at constant 1995

1 Potential output was derived using the Hedrick-Prescott filter methodology. 
Table 1. The Estimation of the Expectation-augmented Phillips-curve Dependent Variable: Quarterly Growth Rate for the CPI (t-statistics in brackets)

\begin{tabular}{|c|c|c|c|c|}
\hline \multirow[b]{2}{*}{$\begin{array}{l}\text { Constant } \\
\Delta s_{1}\end{array}$} & \multicolumn{2}{|c|}{ 1992:Q1-2001Q1 } & \multicolumn{2}{|c|}{ 1995Q1-2001:Q1 } \\
\hline & -25.666 & -19.513 & -38.7876 & -40.157 \\
\hline - current & $\begin{array}{l}-0.144 \\
(-3.04)\end{array}$ & $\begin{array}{l}-0.148 \\
(-3.10)\end{array}$ & $\begin{array}{l}-0.152 \\
(-2.73)\end{array}$ & $\begin{array}{l}-0.159 \\
(-2.88)\end{array}$ \\
\hline - lagged & & & $\begin{array}{l}-0.038 \\
(-0.72)\end{array}$ & \\
\hline$E\left(y_{r}-y_{t}^{*}\right)$ & & & & \\
\hline - current & $\begin{array}{l}25.441 \\
(2.89)\end{array}$ & $\begin{array}{l}19.300 \\
(1.92)\end{array}$ & $\begin{array}{l}50.860 \\
(2.46)\end{array}$ & $\begin{array}{l}50.733 \\
(2.49)\end{array}$ \\
\hline - lagged & & & $\begin{array}{l}-12.567 \\
(-0.60)\end{array}$ & $\begin{array}{l}-11.048 \\
(-0.54)\end{array}$ \\
\hline$\Delta \mathbf{r}_{\mathrm{t}}$ & & & & \\
\hline - current & $\begin{array}{l}-0.689 \\
(-6.08)\end{array}$ & $\begin{array}{l}-0.649 \\
(-5.50)\end{array}$ & $\begin{array}{l}-0.626 \\
(-4.19)\end{array}$ & $\begin{array}{l}-0.655 \\
(2.49)\end{array}$ \\
\hline - lagged & & $\begin{array}{l}0.140 \\
(0.96)\end{array}$ & 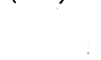 & \\
\hline$\Delta \mathrm{p}_{\mathrm{i}}$ & & & & \\
\hline - current & & $\begin{array}{l}0.210 \\
(1.30)\end{array}$ & & \\
\hline -lagged & & $\begin{array}{l}0.210 \\
(1.30)\end{array}$ & & \\
\hline Adjusted $\mathrm{R}^{2}$ & 0.56 & 0.56 & 0.52 & 0.53 \\
\hline SEE & 1.000 & 1.005 & 1.078 & 1.065 \\
\hline DW & 1.59 & 1.87 & 1.70 & 1.68 \\
\hline
\end{tabular}


prices measures output. The estimation results are given in Table 1.

Four different regressions are represented in Table 1, for two different time periods. The variables are all in 'first differences so that they are stationary. This leads to non-spurious regression results. In all four regressions the independent variables were changed in order to see if the coefficients of the real effective exchange rate and the real interest rate remain stable. The results suggest that this was indeed the case and that the ratio by which the exchange rate and the interest rate influence inflation stays constant across time and parameters. The result indicates that the interest rate influences inflation four times more than the exchange rate. International studies find that this estimation result is in line with other small open economies (Ericsson Hal:. 1998).

Normalising the equation for the MCI with $I=1$, implies that $\mathrm{a}=0.25$. With weights assigned to the parameters, the MCI can now easily be estimated using equation (7). The base period for the MCI was arbitrarily chosen as January 1992. As with any other index, the base period could be easily changed without influencing the results.

From Fig. 1 it can be seen that between 1997 and 1998 monetary conditions were very tight due to the Asian crisis. This is in line with a priori expectations. From 1998 onwards conditions improved gradually. For the first time in May 2000 
monetary conditions improved more than the 1992 level.

Unfortunately, as can be seen, the MCI is declining fast. In part this is due to a fall in the interest rate. But the depreciation of the rand is also to blame. The financial crisis in some South American countries and the political situation in Zimbabwe are triggering huge capital outflows. Going back to the model, this means a rise in $\mathrm{F}$ - net foreign investment. The shock to equation (6) (i.e. $u_{3}$ ) is positive, which leads to a depreciation of our currency (a decline in e).

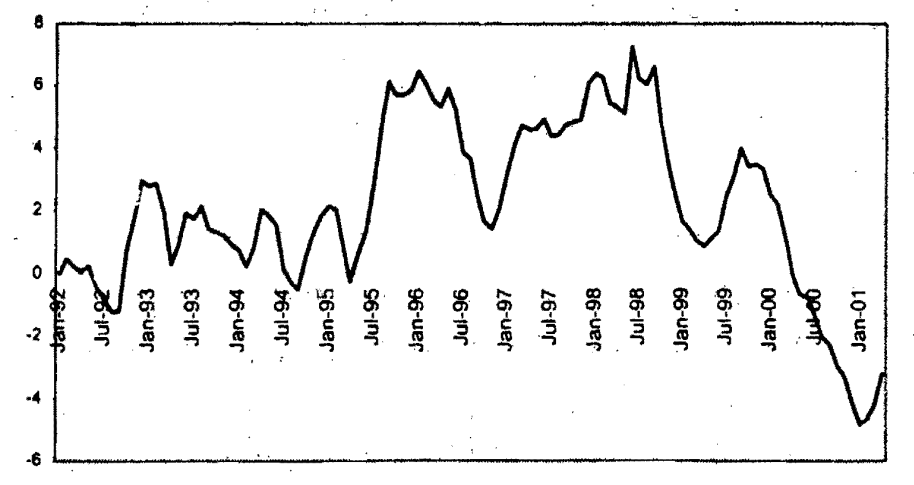

Figure 1. Real MCI for South Africa (January 1992 =0)

If the Reserve Bank wants to keep monetary conditions in the country stable, they should increase the interest rate to keep the 
MCI constant. Keeping the MCI constant will keep inflation at bay and have no huge impact on output.

How does one interpret the MCI? A fall in the index is interpreted as a loosening of monetary conditions, while a rise represents tighter conditions - relative to the base period. In the short run (week-to-week) if the actual MCI rises above the target path, this is considered as a tightening of monetary conditions relative to those anticipated or desired, and the Reserve Bank might consider responding. However, if it becomes apparent that there was a structural change in the economy and that there is a permanent change in the monetary conditions of South Africa the Reserve Bank should respond differently. In this case markets have moved to a new equilibrium and will not return to the same level as before the shock. The Reserve Bank should now move the whole MCI up or down, instead of trying to keep the MCI at its original level.

\section{Some CAVEATS using a MCI}

Like all aids to policy, the MCI should not be treated as a mechanical means of making policy. There are a number of specific reasons why one should interpret the MCI with care.

Although the MCI might be better conceptually than using only short-term interest rates as the operational target for policy, it remains only an information tool, and should not be treated in any way as a fundamental measure of monetary policy. Neither the 
interest rate nor the MCI should be the authorities' ultimate concern. The Reserve Bank's ultimate concern is the rate of monetary expansion and the way it impinges on inflation.

In the very short run one should be careful to use the MCI in an overly mechanical nature. Exchange rates can be quite volatile on a day-to-day basis that should in essence be ignored. Only if it appears that the market has found a new trading range for the rand and that it is permanent, should action be taken to offset this effect on the MCI. Furthermore, there is always some uncertainty about the assessments of the economy and about the transmission mechanisms and its links with changes in aggregate demand and inflation.

It might also happen that in the very short run the Reserve Bank cannot be expected to achieve the desired MCI insofar as it has to cope with disorderly markets. In order to do this, the Reserve Bank might have to raise or decrease interest rates. Over time of course, as market expectations settle down, short-term interest rates could decline to levels more consistent with the desired MCI (Freedman: 1994).

\section{Policy implications}

The Monetary Conditions Index is currently used as an information measure by a few central banks across the world, including New Zealand and Canada (Ericsson et al.: 1998). What is interesting is that most of these central banks also have an 
inflation target as ultimate objective. As can be seen from the model, using the interest rate as an operational target has the potential to lead to greater inflation and output variation if shocks occur mainly to net foreign investment. In order to use the MCI, the focus will have to shift from targeting interest rates to targeting monetary conditions. When the Reserve Bank observes that the MCI is moving away from its target level, they should use their main instruments to influence monetary conditions in order to bring the MCI back to its target level — if the MCI rises, monetary policy should be eased, and if the MCI declines, monetary policy should be tightened, until the MCI returns to its target path. There are many variables that are influenced by monetary policy and the short-term interest rate will be only one of them. The interest rate is not the ultimate target variable and should not be of much concern. Furthermore, to the extent that market participants realise a rise in the short-term interest rate is only temporary, long run interest rates should not be influenced by policy at all.

It might be a bit premature for the Reserve Bank to implement a MCI as rule and guide because South Africa is still moving towards a desired level of inflation. This means that the Reserve Bank will necessarily not be able to keep the MCI constant (because the ultimate target (inflation) is still declining). However, as soon as the desired level of inflation has been reached, and the Reserve Bank perceives monetary 
conditions in South Africa as desirable, the Bank will be able to implement a MCI and keep it constant to maintain a desirable stable monetary environment (i.e. stable inflation). The base period for the MCI will be a period in which markets were stable and the monetary conditions that prevailed were desirable. From there on the MCI should be kept within a target range.

Fig. 1 represents the real MCI for South Africa. A huge problem regarding the use of the real MCI is the fact that CPI figures only become available with lags. In other words, an updated real MCI will not be available on a week-to-week basis, which eliminates it as an operational target. But, if inflation reaches its target level, and is kept constant at that level, the nominal MCI will be the working variable — the real MCI and the nominal MCI will look exactly the same with one on a higher level than the other. As mentioned, it is not the level of the MCI that matters, but how it deviates from its desired path.

If the Reserve Bank uses the Monetary Conditions Index as guide and strategy, it will not only improve consistency in their policy application, but also make monetary policy and conditions more understandable to the general public by increasing transparency. These factors are crucial for inflation targeting in order to keep expected inflation in line with actual inflation (Fischer: 1990: 1172). The MCI can be applied as a strict rule by monetary authorities on what to do with interest rates. However, the MCI as a strict rule will only be effective and successful when the exchange rate movements are marginal. In the current 
case of South Africa, authorities will probably best use a MCI as an important guidepost and not an ultimate rule. Nevertheless, as rule or guidepost, using a MCI and trying to keep it within target bands can help to achieve a more predictable macroeconomic environment.

\section{Conclusion}

The MCI is a relatively new concept and central banks have been reluctant to adopt it for various reasons. It is definitely not a miracle rule that can be applied mechanically by the Reserve Bank to achieve a desired target. It has to be used with judgement and great care.

Even if the South African Reserve Bank does not adopt such an information variable as part of its broader range of indicators, financial institutions, to determine the 'fever' of the South African economy, can use this Monetary Conditions Index. It provides a good, simple and graphic indication of the current monetary situation relative to the previous periods in South Africa.

One has to remember that if only business uses the Monetary Conditions Index, it will appear like Fig. 1 - jumping up and down as conditions change. If the Reserve Bank adopts the Monetary Conditions Index, the index will become a lot smoother (almost a straight line) as the Reserve Bank keeps it within certain target bands. 
Given the nature of shocks to the South African economy, the MCI can help achieve a more stable monetary environment for South Africa.

\section{References}

B.tI.INO and Corlitrit.I.I (1994) Frameworks for Monetary Stability: IMF, Washington BNIJ., L. (2000) Policy Rules and External Shocks: NBER Working Paper 7910.

DUGiU.IY, P. (1994) Empirical evidence on the strength of the monetary transmission mechanism in Canada: An aggregate approach, Joumal of Monetan Eionomits, 33: 39 -61 .

ERRICSSON, N. et.al. (1998) Interpreting a Monetary Condition Index in Economic Policy: in Topics of Mometary Policy Modelling, BIS

FISCHI:R, S. (1997) Rules vs. Discretion in Monetary Policy: in Handbook of Monetan Economics, Volume.2, eds. Friedman, B.M. and Hahn, F.H., Elsevier Science Publisher, North-Holland, pp.1156 - 1184.

FRIEDMAN, C. (1994) The role of monetary conditions and the monetury conditions index in the conduct of policy, Conference on International Developments and the Economic Outlook for Canada, University of Toronto: Toronto

Hunt, B and Orr, A (1999) Inter-forecast monetary policy implementation: responding to unexpected exchange rate developments: RBNZ Bulletin 62(1).

MBowini, T. (2000) A New Monetary Policy Framework: in A Statement of the Monetury Policy Committee, SARB.

POOI.I:, W. (1970) Optimal Choice of Monetary Policy Instrument in a Simple Stochastic Macro Model: Quarterly Journal of Economics, 84: 197 - 216.

SMI:Ts, F. (1997) Financial Asset Prices and Mfonetary Policy: Theory and Evidence: BIS Working Puper 47.

SVI:NSON, L. (1998) Open-Economy Inflation Targeting: NBER Working Paper 6545.

THIIssF, G.G (1995) Uncerlainty and the transmission of monetary policy in Canada, The HERMES-Glendon Lecture, York University: Toronto. 